\title{
Erratum to: Antireflective properties of AZO subwavelength gratings patterned by holographic lithography
}

\author{
J.W. Leem • Y.M. Song $\cdot$ Y.T. Lee $\cdot$ J.S. Yu
}

Received: 3 June 2010 / Published online: 13 July 2010

(C) Springer-Verlag 2010

Erratum to: Appl Phys B (2010) 99: 695-700

DOI 10.1007/s00340-010-4030-x

Due to a processing error the presentation of Figs. 1 and 5

was incorrect. The corrected Figs. 1 and 5 are given here:

Fig. 1 Schematic diagram of the pattern transfer process steps for the fabrication of the SWG structures of AZO deposited on Si substrate

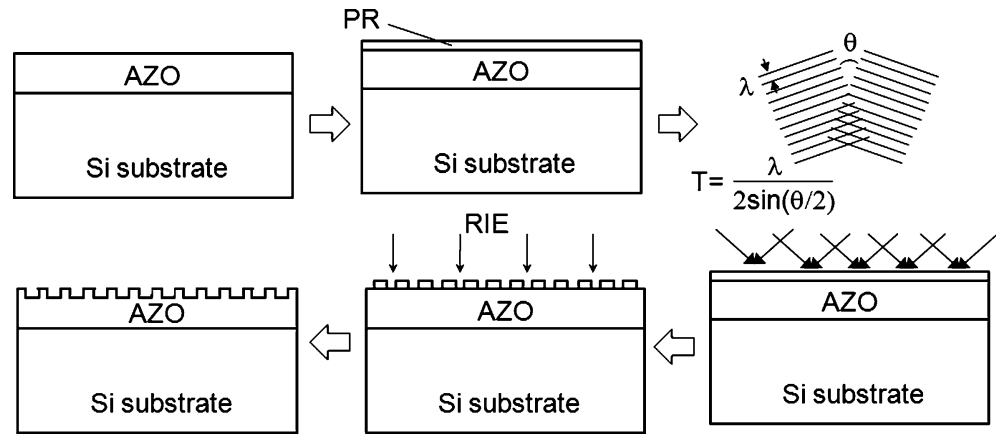

The online version of the original article can be found under doi:10.1007/s00340-010-4030-x.

J.W. Leem · J.S. Yu $(\bowtie)$

Department of Electronics and Radio Engineering, Kyung Hee

University, 1 Seocheon-dong, Giheung-gu, Yongin-si,

Gyeonggi-do 446-701, Republic of Korea

e-mail: jsyu@khu.ac.kr

Y.M. Song · Y.T. Lee

Department of Information and Communications, Gwangju

Institute of Science and Technology, 1 Oryong-dong, Buk-gu,

Gwangju 500-712, Republic of Korea

Y.T. Lee

e-mail: ytlee@gist.ac.kr 


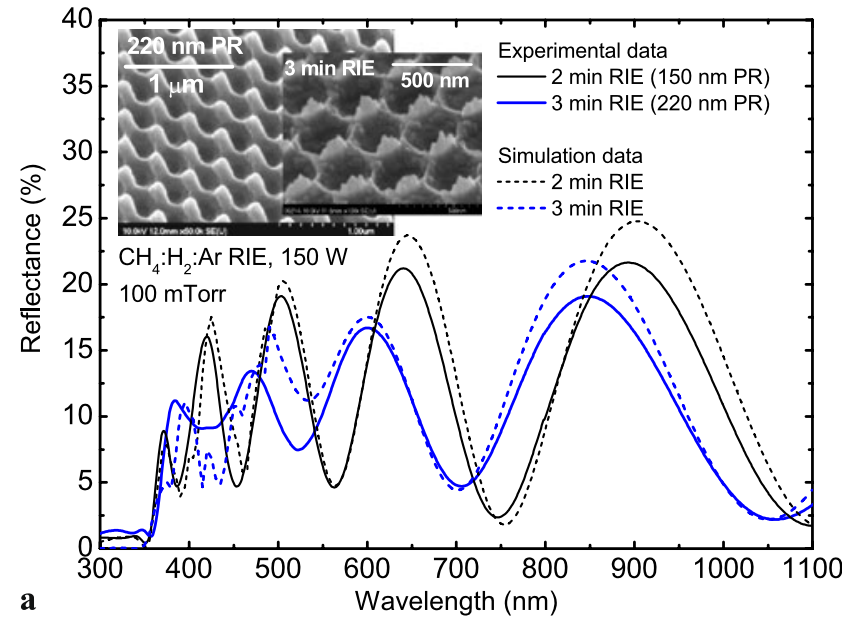

Fig. 5 (a) Measured and calculated reflectance spectra of the fabricated AZO SWG structures on Si substrate using $150 \mathrm{~nm}$ and $220 \mathrm{~nm}$ thick PRs, and (b) calculated reflectance spectra of AZO SWG struc-

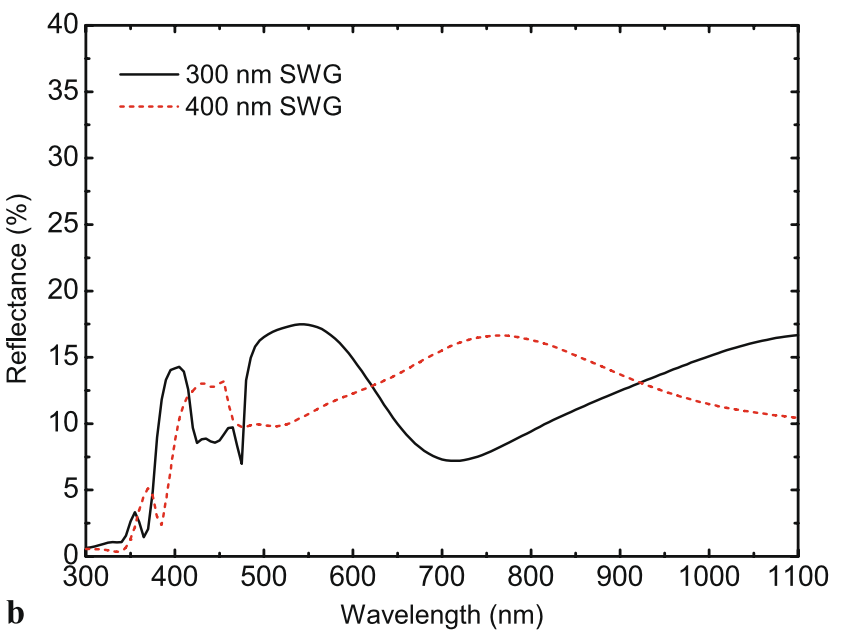

tures with $300 \mathrm{~nm}$ and $400 \mathrm{~nm}$ heights on Si substrate. The inset of (a) shows the SEM images of $220 \mathrm{~nm}$ thick PR patterns and AZO SWG structure with hole arrays after 3 min RIE 